Virginia Commonwealth University VCU Scholars Compass

\title{
Creating a sustainable graduate student workshop series
}

Bettina Peacemaker

Virginia Commonwealth University, bjpeacemaker@vcu.edu

Martha Roseberry

Virginia Commonwealth University

Follow this and additional works at: https://scholarscompass.vcu.edu/libraries_pubs

Part of the Library and Information Science Commons

\section{Downloaded from}

https://scholarscompass.vcu.edu/libraries_pubs/44

This Article is brought to you for free and open access by the VCU Libraries at VCU Scholars Compass. It has been accepted for inclusion in VCU Libraries Faculty and Staff Publications by an authorized administrator of VCU Scholars Compass. For more information, please contact libcompass@vcu.edu. 


\title{
Creating a sustainable graduate student workshop series
}

\begin{abstract}
Purpose - This paper reports on librarians' experience creating and sustaining a workshop and webinar series for graduate students over the course of four years.

Design/methodology/approach - Difficulties hosting and promoting stand-alone graduate workshops and a collaborative method for planning workshop days and webinars are described in this case study. Attendance data were collected and recorded for each event and additional quantitative data were collected via registration forms and post-event surveys.

Findings - Working collaboratively as a department eased planning and promotional responsibilities, allowing for a sustainable workshops series. Focusing on a limited number of events per semester and developing a brand identity for the series streamlined promotion and increased attendance, relative to discipline-based, stand-alone workshops.
\end{abstract}

Originality/value - While many libraries host workshops, the originality of our program lies in the collaborative planning and promotion process that efficiently uses librarian time and expertise to continuously offer well-attended graduate workshops and webinars. This case study could be used as an example for institutions considering starting a workshop series or those experiencing difficulties with stand-alone workshops.

Paper type - Case study

Keywords - workshops, academic libraries, graduate students, marketing, promotion, library instruction, library liaisons 


\section{Introduction}

Academic Outreach librarians at Virginia Commonwealth University (VCU) are responsible for discipline-based outreach to upper level undergraduates, graduate students, and faculty. While all of these groups present their own challenges, graduate students often stand out as "misunderstood, elusive, or hard to reach" (Baruzzi and Calcagno, 2015, 401). This elusiveness is problematic given the reported gaps in information literacy among graduate students (Conway, 2011; Harris, 2011) and their lack of knowledge about library resources and services (Gibbs et al., 2012; Washington-Hoagland and Clougherty, 2002).

Instruction commonly is cited as a tactic to connect with graduate students and advance their research skills, but there are obstacles to reaching this group with course-integrated instruction and library orientations. It is difficult to scale a curriculum-integrated approach across the multitude of master's and doctoral programs at a large university. Students do not come to graduate school with the same undergraduate library instruction experience (Hoffmann et al., 2008). Orientations provide an opportunity to introduce new graduate students to the library, but they are typically limited in terms of time and depth (Rempel and Davidson, 2008). They are also scheduled when students are overwhelmed with information about a new program and a new campus (Gibbs et al., 2012). Individual or small group research consultations are popular (Baruzzi and Calcagno, 2015; Roszkowski and Reynolds, 2013) but by definition focus on a small set of students and topics. Workshops have the potential to reach a broader audience and cover more in-depth research skills useful to graduate students. Unfortunately, this potential remained unfulfilled for Academic Outreach librarians at VCU for a number of years.

VCU is a large, public research university with a total enrollment of 31,231 students offering over a hundred master's and doctoral programs. There are 5,259 graduate and 1,760 first 
professional students across thirteen schools and one college (Virginia Commonwealth University, 2017). VCU has two campuses in Richmond, Virginia, each with a library. The Academic Outreach department is housed at Cabell Library on the Monroe Park campus and consists of nine liaison librarians supporting programs in the humanities, arts, sciences, engineering, social and behavioral sciences, business, and education--serving over 3,000 graduate students.

Academic Outreach librarians work with faculty and students at all levels in their departments and schools but as noted above, graduate students stand out as a challenge. During the 2012-13 academic year, the department reported only 78 course integrated instruction sessions and nine orientations for graduate student audiences. There were some attempts to compensate with workshops. Driven by individual librarian interest, workshops were scheduled on an irregular basis, driven by individual librarian interest with little attention to promotion, and were not well attended. Only six workshops were held during 2012-13 with an average attendance of just two. Based on these remarkably low attendance numbers, the department ceased workshops altogether. Librarians still felt workshops were an important tool to fill gaps in the instruction program for graduate students, but it would be necessary to address the lack of planning and promotional support that ultimately resulted in poor attendance and wasted effort. In response, the Academic Outreach department developed the Advance Your Research series to pool librarian expertise and concentrate planning and promotion efforts. This cases study details the process that allowed us to build a successful and sustainable workshop series.

\section{Literature Review}

A review of the literature indicates that workshop attendance is a challenge for libraries despite interest from graduate students. Bussell et al. found that in-person workshops were one of 
the most preferred formats for instruction, even with a history of poor attendance (in press). Similar to the problem Academic Outreach librarians faced at VCU, the walk-in workshops at the University of Vermont were offered at the convenience of the librarians and suffered from low attendance (O’Malley and Delwiche, 2012). Roszkowski and Reynolds also faced poor attendance from an existing drop-in workshop program (2013). In both cases, librarians successfully revitalized their workshop program by instituting a new planning and promotion process. The literature includes additional examples of graduate student workshop practices that provide some guidance for planning a new or a newly refreshed workshop series (Critz et al., 2012; Fong et al., 2016; Hoffmann et al., 2008; Rempel and Davidson, 2008).

The literature suggests workshop planning should be a collaborative process. That may mean working with a team of knowledgeable librarians and/or campus partners. For example, Critz et al. worked with the Graduate Student Government Association (2012), and Fong et al. created a "Graduate Student Support Group," a librarian-led group with representatives from the Graduate School, Research Office, Writing Center, Learning Center, and Computing Services (2016). Some sought additional insight from graduate students with surveys and/or focus groups (Fong et al., 2016; Hoffmann et al., 2008; Rempel and Davidson, 2008; Roszkowski and Reynolds, 2013). Methods varied, but the resulting workshops were developed with the specific needs of graduate students on a specific campus in mind.

The timing of workshops is one of the needs that is highlighted as a particular challenge. Roszkowski and Reynolds sum up the difficulty of scheduling workshops, "Students were busy, often not on campus, and had trouble coming to workshops, even when they were interested in session content" $(2013,230)$. In their case, they were able to add Saturday sessions to evening weekday options to accommodate their students' schedules, who were all in social sciences 
programs. Other cases were not as clear. For example, Hoffmann et al. surveyed 274 graduate students across four different schools and found no pattern for preferred time of day (2008). Across the other examples, workshop scheduling varied greatly, but librarians did their best to match workshops to their graduate students' schedules.

Because workshop attendance was a major concern for many libraries, it is not surprising that libraries have focused on enhanced marketing efforts. Critz et al. created a branded series, GLUE (Graduate Library User Education) to "make the classes stand out and emphasize them as a united whole" $(2012,534)$. Other tactics included distributing messages on LibGuides, flyers and/or by email and leveraging relationships with campus groups in direct contact with students including faculty, advisors, the Graduate School, academic departments, and student organizations (Critz, 2012; O’Malley and Delwiche, 2012; Rempel and Davidson, 2008; Roszkowski and Reynolds, 2013). In general, librarians considered the available channels of communication that worked best for graduate students.

The actual content of workshops sessions stands out as one of the most important planning details. In a survey conducted by Hoffmann et al., graduate students identified "topics relevant to my work" and "learning what I need to know" as the top incentives for workshop attendance (2008). Fong et al. surveyed 233 graduate students and found that top topics of interest for workshops fell primarily within the research, career, and grant support categories (2016). One of the most common topics covered was literature reviews, but sessions also covered other areas important to graduate students and their research including citation management, current awareness, the publication process, research funding, software or technology training, and key resources. Once again the exact specifics varied, but session topics were tailored to the research needs of graduate students. 
The literature also highlighted the importance of a continuous planning cycle, one that uses feedback from participants, partners, and instructors to inform future plans. Critz et al. notes the success of their "workshop series will remain dependent on this continual scanning of the graduate landscape, and on the course corrections implemented based on an ongoing assessment of graduate student wants and needs" $(2012,540)$. This iterative framework allows for experimentation while also looking forward to sustainability.

The examples highlighted in the literature helped us focus efforts on few key areas to build a more successful workshop program at VCU. Previous attempts at workshops were timeconsuming for librarians to plan and were poorly attended. The attendance did not justify the effort expended preparing for the sessions. With this this in mind, we set a goal of increasing attendance through building a collaborative, iterative process that would allow us to prepare responsive, relevant content and efficiently promote workshop sessions.

\section{Implementation}

The conceptual foundation for the new workshop series at VCU was worked out during discussion at a single department meeting. The department decided to focus on a day-long event held once during the fall and spring semesters. Each workshop day would include between five and seven consecutive workshops, covering topics such as literature reviews, reference management, publishing, and other topics of interest to graduate students. Attendees could choose to attend just one session, or stay for the entire day. Holding a workshop day, rather than several stand-alone workshops, reduced the overall logistical work, such as catering and roomsetup and allowed librarians to focus all of their energy on promoting a single event each semester. The series also included one webinar per semester, with a topic related to the workshop day, to engage with students unable to attend the workshop day. 
Working as a department improved the overall planning process, but it was difficult and inefficient for the entire department to consider every small decision. A managing committee with four members was formed to organize the day and deal with logistics. Each semester, the committee suggested dates, coordinated the promotion, and dealt with event planning details related to room setup, registration, catering and follow-up surveys. For webinars, the managing committee also helped the presenter with the technology, both setting up the online classroom and supporting them during the session.

The system we developed resulted in three tiers of planning. Individual librarians prepared their instructional content and wrote the promotional copy for their workshops. The managing committee dealt with the logistics of planning and promoting an event. The entire department worked together on key decisions including the topics covered. Although members

of the managing committee shouldered more of the work, the membership of the committee was flexible and could rotate based on individual availability. More menial tasks, such as printing handouts, were often planned by the managing committee but delegated to whomever had a spare hour. The end result was a streamlined and easily sustained planning process where the entire department contributed, and no single librarian was responsible for everything.

\section{Promotion}

The attention to process helped ease the burden of planning a workshop series, but we needed a focus on new methods of promotion to boost attendance. We started by building an identity that would be recognizable but flexible enough to use for years to come. The series was titled Advance Your Research--a simple, clear, and memorable title. We used a consistent design with distinctive imagery and concise language across all of our promotional materials. We also 
established a template for print rack cards, as shown in Figure 1, and other elements of the campaign, so we could simply replace the time, date, and session information.

[Figure 1. Advance Your Research rack card ( 8.5 x 3.75 inches)]

One member of the managing committee investigated the possible promotional options available at VCU. After just a couple iterations, a relatively simple promotion plan was developed.

- Set up a registration system to get an attendance estimate and for participant communication. We started with Google forms, but we currently use LibCal, a Springshare product, to manage registrations.

- Build a web presence. We have an Advance Your Research page as part of our library events page. We use a friendly URL, go.vcu.edu/ayr, that easily fits on print materials.

- Coordinate with the Director of Communications and Public Relations to utilize the university-wide student and faculty/staff email, library social media, the university calendar, and any additional broad communication channels regularly managed by that office.

- Create and distribute rack cards (Figure 1). These are given out at orientations, instruction sessions, and outreach events. We also have them in our graduate student reading room.

- Collect email addresses of registrants and participants (sign-in sheet) to send reminders, post-event information, and collect feedback. Automated reminders are sent before the 
event. We also send a follow-up email immediately after the sessions with a link to a survey and a guide with session material including any recordings, slides, and handouts.

- Explore possible e-communication options. We use MailChimp to create an invitation that we send to a list we have built from registrants and past attendees. Emails are sent out about two weeks before the event and then again the week of the event.

- Pursue more targeted approaches for individual departments and units including their listservs, social media, bulletin boards, and even individual contacts. Librarians and partners are given materials, so that they can promote the workshops to their own constituents.

The focus on promotion has benefited our entire outreach effort. We found that the plan we developed for workshops was also effective for other programs and events targeted at graduate students. It was also an effective starting place for other audiences, and we have taken what we have learned and applied it to all of our promotion, adapting it when necessary.

\section{Iteration and Experimentation}

All of the the initial planning for the Advance Your Research series was based on previous experience with graduate students. There was no extensive needs assessment. Thus, building in a collaborative, continuous cycle of feedback from the start would be critical to the sustainability and the ongoing success of the series. Although small changes have been made with each semester's iteration, there are areas of experimentation that are more noteworthy.

A large body of new, relevant instructional content was developed by experimenting with workshop topics. Some topics (e.g. reference management) were based on successful courseintegrated instruction sessions. New areas we felt would be of interest to graduate students (e.g. 
research poster design) were explored as well, along with those librarians wanted to learn more about (e.g. data visualization). A complete list of workshop topics can be found at http://guides.library.vcu.edu/ayr/. Attendees are surveyed after each event to ask for topic suggestions, but low response rates and a lack of consensus among respondents has made this less useful than anticipated. Despite this, using our intuition and information gleaned from conversations with graduate students and faculty has served us well. Advance Your Research has become a venue where librarians can test drive workshop ideas, allowing us to increase our catalogue of topics--for workshops and also for use in other instruction sessions.

Another successful experiment was the inclusion of librarians and others beyond Academic Outreach. Collaborating with others took some of the strain off the department, while at the same time enriching the variety of content offered. With the help of other librarians around the library, we have presented workshops on data management, personal archiving, systematic reviews, and scholarly communications and copyright. For our most recent Advance Your Research workshop day, a professional from VCU Career Services presented a workshop on informational interviewing, further expanding our repertoire.

One of our biggest changes since the first workshop day was the introduction of Saturday workshops. Choosing a good day of the week for a workshop was troublesome. There was so much conflicting feedback from students and librarians that we just kept trying different days. One librarian believed Saturday would be the best day for graduate students who often balance their studies with work and family obligations during the week. For this reason, the Spring 2015 workshop day was held on a Saturday. Not only did Saturday prove to be a convenient day for graduate students to attend, but as it is a relatively quiet day in the library, it was easier to secure space in the building and set up the classroom in advance. 
Some experiments did not work. To determine if our new promotion strategy would prompt graduate students to attend sessions outside of the workshop days, we held a stand-alone, in-person Advance Your Research workshop in Spring 2014. It attracted only two attendees, and no additional in-person, stand-alone sessions have been planned.

Stand-alone online sessions have been much more successful, possibly our most successful experiment. Although most of VCU's graduate students are local, many prefer the webinars or find them easier to attend. Academic Outreach librarians had no experience holding them on a regular basis, but we were able to easily adapt our workshop planning and promotion process for webinars. As with the workshop day, the librarians presenting the webinars were responsible for the content, either creating a webinar from scratch or modifying the content of a workshop for an online platform, while the managing committee dealt with the logistics. After four years this process has been streamlined, and webinar planning and promotion has been integrated into the overall workshop series strategy.

\section{Assessment}

While attention to the planning process eased the workload, the primary goal we set for Advance Your Research was to have more graduate students attend library workshops. Thus, we used attendance as a measure of success. In Figure 2, the attendance for each session within a workshop day is represented by a circle and the average attendance over the entire day is shown using a black bar. The workshop day with the lowest average attendance, Spring 2016, was still much better than attendance at previous standalone workshops, at which we were lucky to get one or two people.

[Figure 2. Workshop day attendance.] 
Particularly in the fall, holding workshops on a Saturday seems to boost attendance. In general, the fall workshop days have had better attendance and the last two spring workshop days, although still respectable, have been disappointing. It is possible that students have more availability in the fall or that advertising the series during the many fall orientations increases attendance. Further experimentation is needed to identify factors that will improve attendance for spring workshop days. Alternatively, if attendance continues to be low, we will discontinue the spring workshop day in favor of additional webinars.

We have also tracked attendance at our webinars, shown in Figure 3. Most of our webinars have had approximately 30-50 attendees, which means we typically have greater attendance at the webinars than at the workshop days. The Fall 2015 webinar had a record setting attendance of 105. Variations in attendance, we believe, are due largely to the topic choice. For example, the topic for the Fall 2015 webinar was "How to Start Your Lit Review," a topic relevant to all graduate students regardless of their field of study. Overall, we have been pleased with the attendance at our webinars and believe them to be a valuable part of the series.

[Figure 3. Webinar attendance.]

Registration data also suggests that the series, including both workshop days and webinars, is meeting the goal of attracting graduate students across all fields. It should be noted that not all registrants attend, but the registration form and sign-in sheet collect data on academic status and discipline for registrants. Of the registrants who indicated a status, $82.9 \%$ were graduate students, $17 \%$ were faculty and $0.2 \%$ were undergraduates. Figure 4 shows the 
distribution of the 738 registrants with known discipline. Although not entirely aligned with the distribution of graduate FTE at VCU, shown for comparison (Virginia Commonwealth University, 2016), the series has registrants from all of the schools and colleges, reaching a diverse set of graduate students.

[Figure 4. Discipline distribution of Advance Your Research registrants.]

As the implementation of the Advance Your Research series included a focus on promotion, we were interested in assessing the success of the Advance Your Research identity. Assuming those who recognized the identity would be more likely to recognize promotion and register repeatedly, we looked at how many registrants had registered for multiple events. This was done by comparing the email addresses used to register. A total of 146 people registered for more than one event, with 45 registering for three or more events. Although somewhat encouraging, this is not enough evidence to indicate whether or not people recognize the series identity.

Along with the quantitative attendance and registrant data, we also considered feedback from attendees to assess the success of the series. After each event, registrants and attendees are sent a follow-up survey, Figure 5. We have received a total of 129 responses over four years. Although the response rate has been low (less than 13\%), most respondents rated the workshops and webinars favorably. Of the 119 respondents who rated their overall experience, $98.3 \%$ rated it as good or excellent. The survey also allowed for open-ended comments. Most of the comments received were very complimentary. For example, "I am so impressed with all of the fabulous resources the library provides for students" and "One of the best, most useful 
workshops I have ever attended... Absolutely superb !!!”. Most comments are generic and difficult to attribute to a specific workshop, but positive comments that specifically mention the topic or workshop have helped us determine which topics are successful and should be considered for a repeat performance. A few of the comments provided suggestions, such as offering CE credits. We have received only four negative comments, and two of those were from attendees who had difficulties connecting to the webinars.

[Figure 5. Follow-up survey from the Spring 2017 Advance Your Research workshop day.]

While promoting to "graduate students" as an audience is helpful, they are a diverse group with needs that vary by skill level and discipline. One of the negative comments from attendees noted that "it was a basic level workshop but I expected an advanced level." However, it is clear from other comments and in-person feedback that many of our attendees require more introductory sessions. Not all registrants attend, so it is difficult to accurately pre-survey attendees to assess skill level. However, we may be able to market some workshops and webinars as "advanced" to address a higher skill level.

It is also difficult to produce relevant content without a subject focus. One attendee noted that the "content of each session covered too wide areas...it [would] be more helpful to [target] people in the field." Initially, we thought that the series could be replicated for specific academic schools or departments, but currently workshop days are not a scalable solution for disciplinespecific outreach and education. Even with the blueprint established by the department's Advance Your Research effort, an individual librarian does not have the resources required to publicize and host a workshop series. However, liaison librarians are inspired by content from 
colleagues to expand their own offerings. For example, material from the workshops on literature reviews has been modified and tailored for use in presentations to engineering graduate student seminars and the data visualization webinar has been repurposed for both a technical writing course and a systems modeling and analysis course.

\section{Discussion}

We accomplished our goal of creating a workshop series that graduate students attended in numbers more in line with the librarian effort required to deliver that instructional content. The planning process is efficient, allowing librarians to focus on high quality instructional content that they know will be delivered for a relatively stable audience. Anecdotally, the librarians' response remains enthusiastic to the ongoing process with full participation from Academic Outreach, as well as continued collaboration with other departments around the library. Three areas stand out as reasons for our success at maintaining a healthy attendance at workshops in an efficient manner and may offer guidance for others.

\section{Experimentation}

The ability to experiment allows the department to continually produce high-quality workshop content and hone the planning process. Being open to new ideas and solutions will allow us to sustain this effort for as long as it works. A good example of this potential is the introduction of Saturday workshop days. When one of the librarians suggested Saturday, there was skepticism. However, we built an environment that encouraged experimentation, so it seemed like a low-risk proposition. Ultimately, it turned out to be the best day of the week, at least for fall workshops. We will continue to monitor the impact of having the workshop day on Saturdays. There may be a case to try other days as we proceed, and the system easily allows that. 
For this iterative process to work, it is important to document everything. The planning process is well documented and revisited often based on any data we collect along the way. So far, the planning team has been fairly static, but with the documentation, it would be easy to rotate responsibilities while continuing to build on what we have learned so far.

\section{Focus on promotion}

Prior to Advance Your Research, the promotion plan for workshops was haphazard at best relying heavily on word-of-mouth, which simply is not enough. Building an identity and strategy allows us to more effectively advertise workshops. While we do not have strong evidence that the students recognize the brand, Advance Your Research, it is clear that we do. That attention to promotion, in and of itself, increases the energy around the department for actively promoting the series. It also helps as we have looked around the library and university for partners and for help reaching new audiences.

The promotion strategy contributes to the series' sustainability in other ways. Since the campaign draws on common imagery and messaging, we do not create new promotional materials from scratch for each iteration. This allows us to invest in professional-grade materials that only occasionally need to be updated. There is still room for experimentation as we look for areas that will have the most impact. For example, our high attendance at the fall 2016 workshop day corresponds to the first time we had rack cards ready in time for all orientations. While there is no conclusive evidence that the print material alone increased registration, there is an incentive for us to have materials ready early for fall 2017.

\section{Planning as a team}

Planning and promoting a workshop series is a labor-intensive undertaking, so having an entire department pitching in helps make the work manageable. Moreover, a collaborative 
process instills a strong sense of ownership that encourages sustained participation and enthusiasm both in producing instructional content and promoting the series.

It is impossible for any one librarian to meet the diverse needs and demands of graduate students on their own. Taking a team approach allows us to leverage the talents and expertise of the entire department. While librarians started with the workshop topics most familiar to them, they have also learned from each other. With a starting place and increased confidence about their knowledge on a topic, some librarians are venturing into new territory for instruction and outreach in their subject areas.

Librarians also benefit from new perspectives from their library peers and students outside their subject area. For example, an arts research librarian gets different feedback about copyright issues from science and social work students than they do from their typical audience of artists. This allows librarians to explore new areas of growth and extend their expertise.

As we look to the future, we must also look for new partnerships. There are many pieces of the research enterprise where the library does not hold all of the expertise. We have extended our planning team to include health sciences librarians and invited external speakers, and there are many more areas to explore that would advance graduate research.

\section{Conclusion}

Although we continue to experiment to ensure all events have satisfactory attendance, the Advance Your Research series is currently the right size and scope for our department. The instruction space is outfitted with 36 chairs, so the Fall 2016 workshop day nearly over-filled the room. That being said, we can still work to improve the series. Advance Your Research is now four years old, and we have presented 49 workshops and webinars. With a method for planning and promoting the series in hand, seeking additional feedback and evaluating the workshop 
content more systematically will help us build on the success. Advance Your Research can continue to be a venue for testing topics. However, compiling some of the most well-received workshops into a "best of" list, with lesson notes and materials available to all, will allow us to easily repeat popular workshops for the series, as well as making it easier for librarians to adapt and reuse the content for other instruction. We should also leverage our audience's interest in webinars. We currently host two webinars a year. Both the technology and our familiarity with it are improving, so we can increase this number. Material used for webinars may also be repurposed to make on-demand instructional videos.

By 2013, Academic Outreach had given up on stand-alone workshops due to lack of interest and attendance. By focusing the energies of the entire department on the Advance Your Research series, we now have a robust series of workshops and webinars helping us increase our outreach to graduate students. Our collaborative approach to planning means that each librarian's expertise is used, and no individual librarian is responsible for everything. The strong sense of identity for the series allows us to promote each event professionally with ease. The system we created allows for experimentation and flexibility--ultimately allowing us to sustain efforts for years to come.

\section{References}

Baruzzi, A. and Calcagno, T. (2015), "Academic librarians and graduate students: An exploratory study", Portal: Libraries \& The Academy, Vol. 15 No. 3, pp. 393-407.

Bussell, H., Hagman, J. and Guder, C.S. (In press), "Research needs and learning format preferences of graduate students at a large public university: An exploratory study”, College \& Research Libraries, available at http://crl.acrl.org/index.php/crl/article/view/16617/18063 (accessed 21 June 2017). 
Conway, K. (2011), "How prepared are students for postgraduate study? A comparison of the information literacy skills of commencing undergraduate and postgraduate information studies students at Curtin University", Australian Academic \& Research Libraries, Vol. 42 No. 2, pp. 121-135.

Critz, L., Axford, M., Baer, W.M., Doty, C., Lowe, H. and Renfro, C. (2012), "Development of the graduate library user education series", Reference Services Review, Vol. 40 No. 4, pp. 530-542.

Fong, B.L., Wang, M., White, K. and Tipton, R. (2016), “Assessing and serving the workshop needs of graduate students", The Journal of Academic Librarianship, Vol. 42 No. 6, pp. $655-663$.

Gibbs, D., Boettcher, J., Hollingsworth, J. and Slania, H. (2012), “Assessing the research needs of graduate students at Georgetown University", The Journal of Academic Librarianship, vol. 38 No. 5, pp. 268-276.

Harris, C.S. (2011), "The case for partnering doctoral students with librarians: A synthesis of the literatures", Library Review, Vol. 60 No. 7, pp. 599-620.

Hoffmann, K., Antwi-Nsiah, F., Feng, V. and Stanley, M. (2008), "Library research skills: A needs assessment for graduate student workshops", Issues in Science \& Technology Librarianship, Vol. 53.

O'Malley, D. and Delwiche, F.F. (2012), “Aligning library instruction with the needs of basic sciences graduate students", Journal of the Medical Library Association, Vol. 100 No. 4, pp. 284-290.

Rempel, H.G. and Davidson, J. (2008), "Providing information literacy instruction to graduate students", Issues in Science and Technology Librarianship, Vol. 53. 
Roszkowski, B. and Reynolds, G. (2013), “Assessing, analyzing, and adapting: Improving a graduate student instruction program through needs assessment”, Behavioral \& Social Sciences Librarian, Vol. 32 No. 4, pp. 224-239.

Virginia Commonwealth University, Office of Planning and Decision Support. (2016), "Fall FTE by School/College and Student Level", available at http://www.opds.vcu.edu/media/decisionsupport/factandfigures/enrollment/enrollmentfall2009-16fte.pdf (accessed 29 March 2017).

Virginia Commonwealth University. (2017), "Facts and Rankings", available at http://www.vcu.edu/about/facts-and-rankings.html (accessed 28 June 2017).

Washington-Hoagland, C. and Clougherty, L. (2002), "Identifying the resources and service needs of graduate and professional students: The University of Iowa user needs of graduate professional series", portal: Libraries and the Academy, Vol. 2 No. 1, pp. 125143. 
Figure 1. Advance Your Research rack card (8.5 x 3.75 inches).

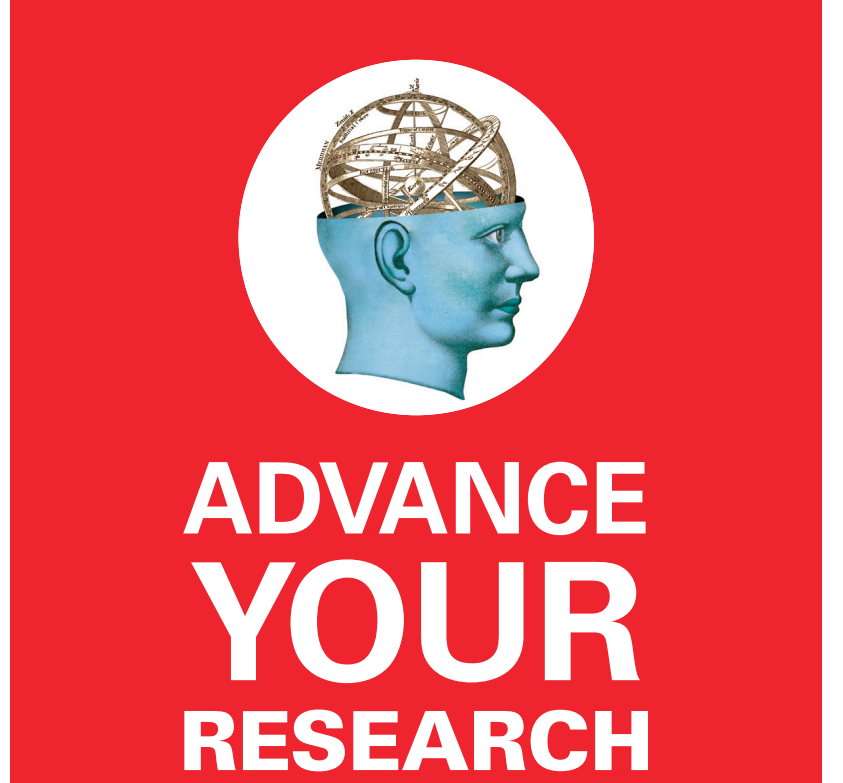

Saturday, Oct. 15, 2016 10:30 a.m. - 4 p.m.

James Branch Cabell Library, Room 205

Workshops for graduate students and other advanced researchers designed to help make your research process better, faster and smarter.

\section{Topics:}

- Grant writing

- VCU centers and services

- Online academic identity

- Reading academic articles

- Reference management

Free and open to all. First come, first seated.

Sign up: go.vcu.edu/ayr

\section{Schedule of Workshops}

\section{Saturday, Oct. 15, 2016}

10:30 a.m. - 4 p.m.

\section{James Branch Cabell Library}

\section{Room 205}

10:15 a.m.

\section{Check-in}

Enjoy a light breakfast and network.

\section{0:30 a.m.}

Ideas for Grant Writing

Top tips for the search, writing and review process.

\section{1:30 a.m.}

\section{Resource Round-Robin}

Meet representatives for VCU's centers and services that can help you with your research.

\section{2:30 p.m.}

Lunch with Your Librarian

Join us for lunch and informal conversations with library colleagues.

Please sign up for lunch at: go.vcu.edu/ayr

1 p.m.

Uniquely You: Establishing a Digital Academic Identity Learn how to use tools like ORCHID and Google Scholar to raise your online academic profile.

\section{2 p.m.}

Reading for Quality

Discover how purposefully reading articles can improve your own research methods.

\section{3 p.m.}

Better Reference Management through Technology

Save time, toil and trouble by organizing your sources and references using RefWorks, Zotero and Mendeley. 
Figure 2. Workshop day attendance.

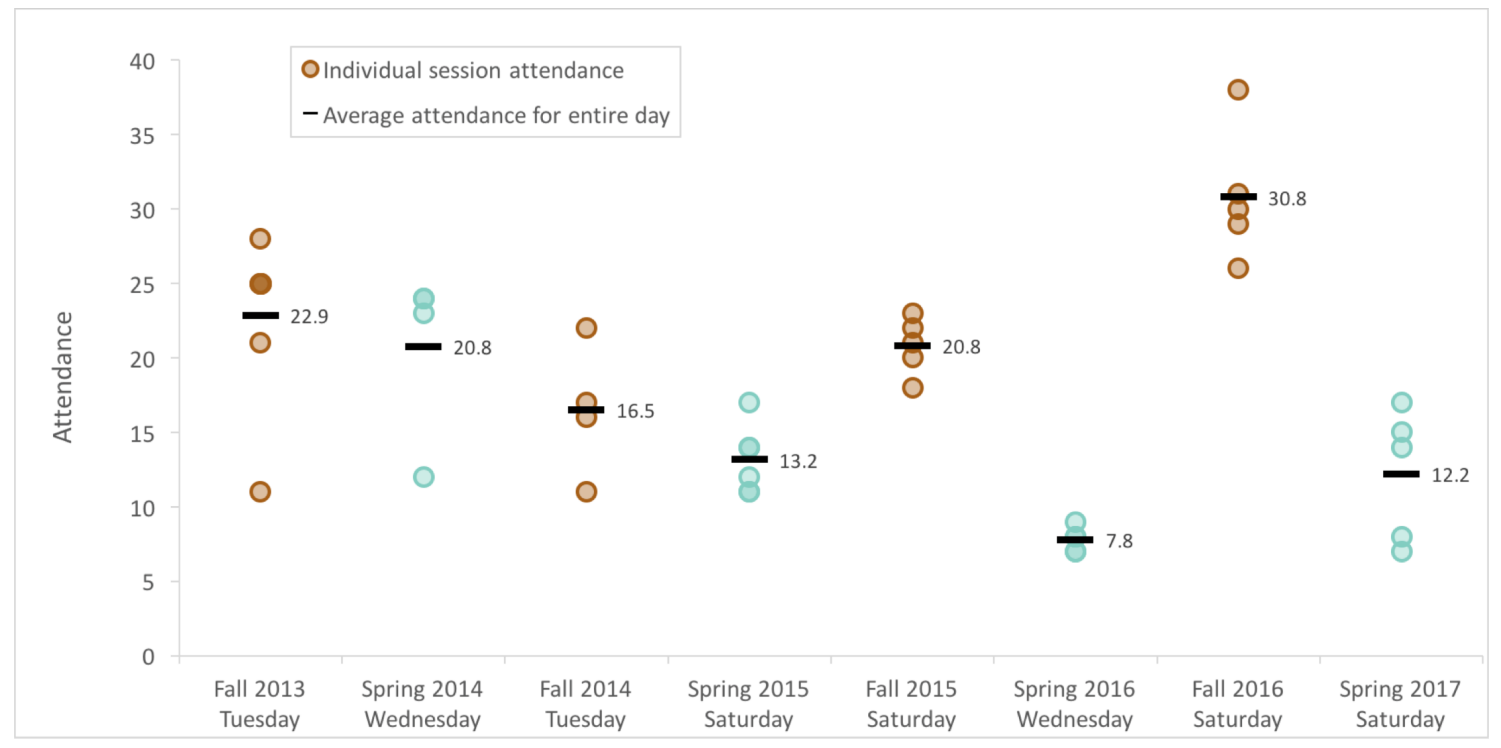


Figure 3. Webinar attendance.

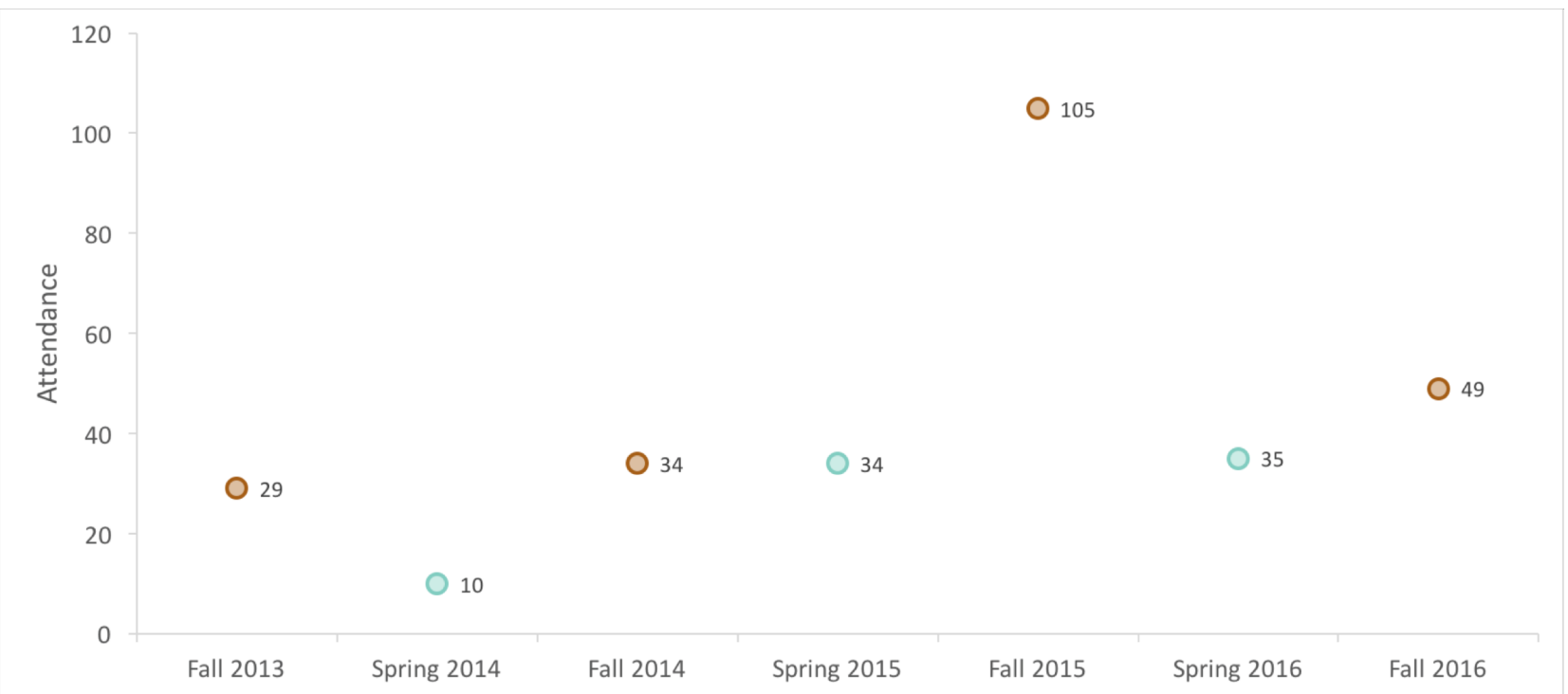


Figure 4. Discipline distribution of Advance Your Research registrants.

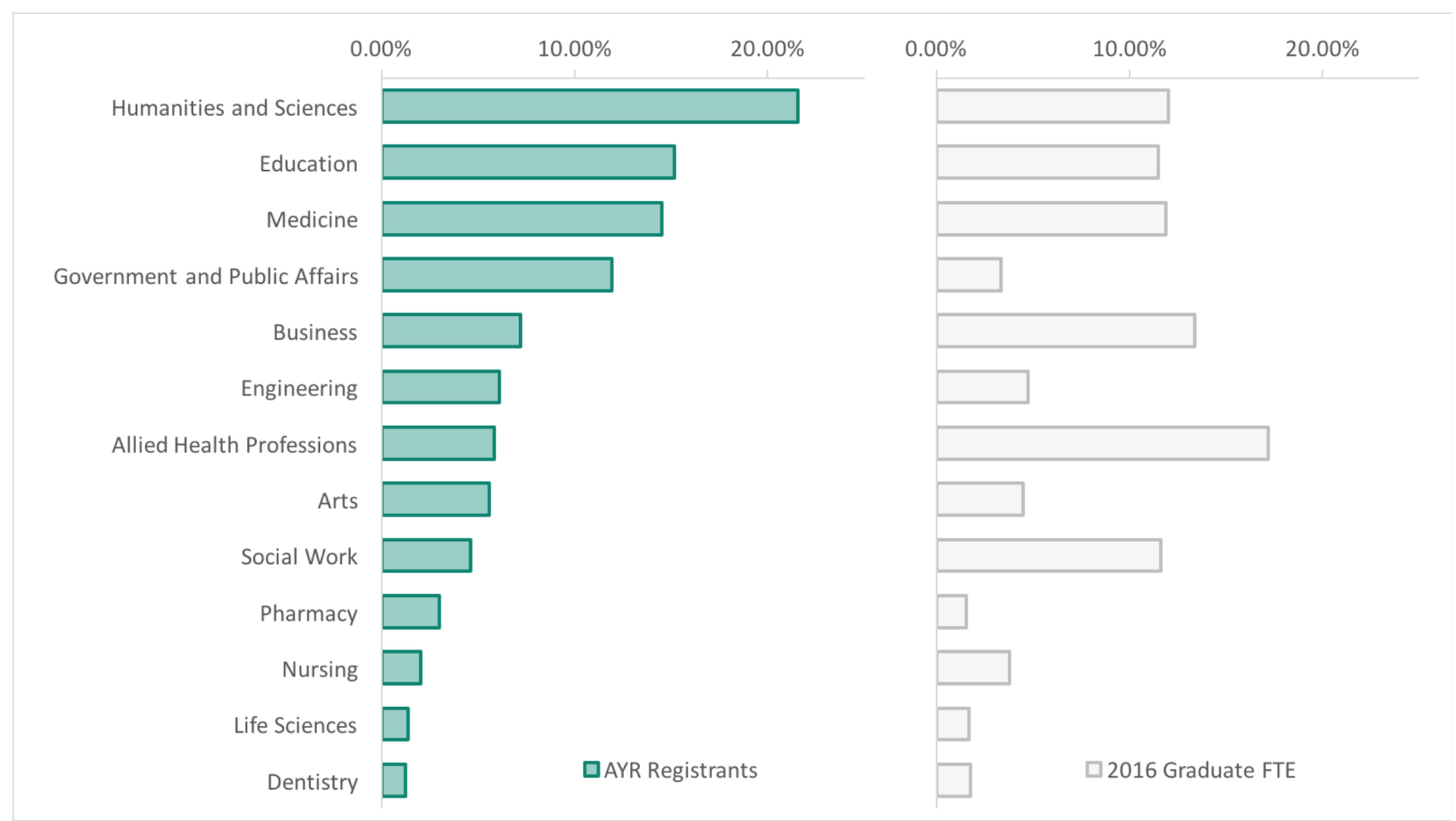


Figure 5. Follow-up survey from the Spring 2017 Advance Your Research workshop day.

\section{Advance Your Research Spring 2017: Followup Survey}

How did you hear about this event? Please mark all that apply.

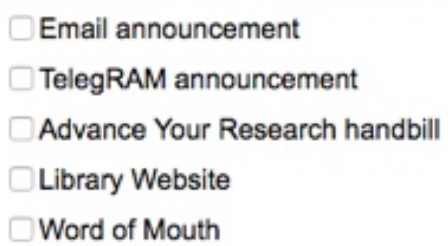

Which workshops were you able to attend?

$\square$ Informational Interview

$\square$ Career Speed Networking

Lunch with Your Librarian

$\square$ Get More out of Google

$\square$ Don't be a Cuationary Tale

$\square$ Library Access After Graduation and Without Affiliation

$\checkmark$ I was not able to attend

Please rank the following aspects of the Advance Your Research workshop day.

Very Poor Poor Good Excellent N/A

Workshop Topics

Presenters

Venue/Location

Food

Overall Experience

What topics, new or old, would you like us to host workshops or webinars on in the future?

Do you have any additional comments? 